
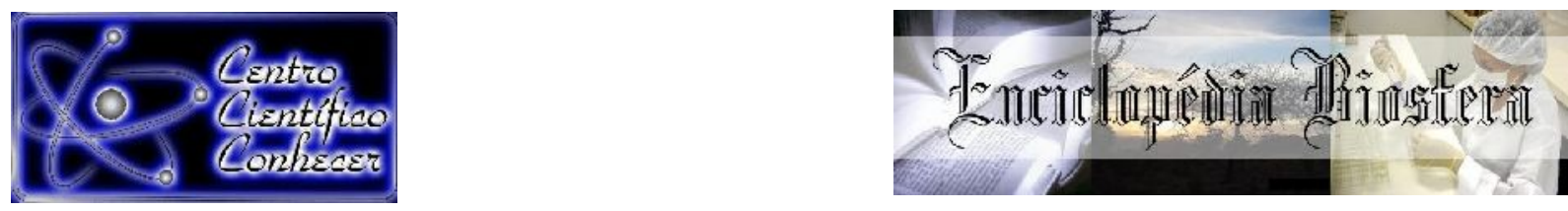

\title{
POTENCIAL ALELOPÁTICO DO EXTRATO DA PARTE AÉREA DO NABO FORRAGEIRO (Raphanus sativus L.) SOBRE O CRESCIMENTO INICIAL DO MILHO (Zea mays L.) EM CASA DE VEGETAÇÃO
}

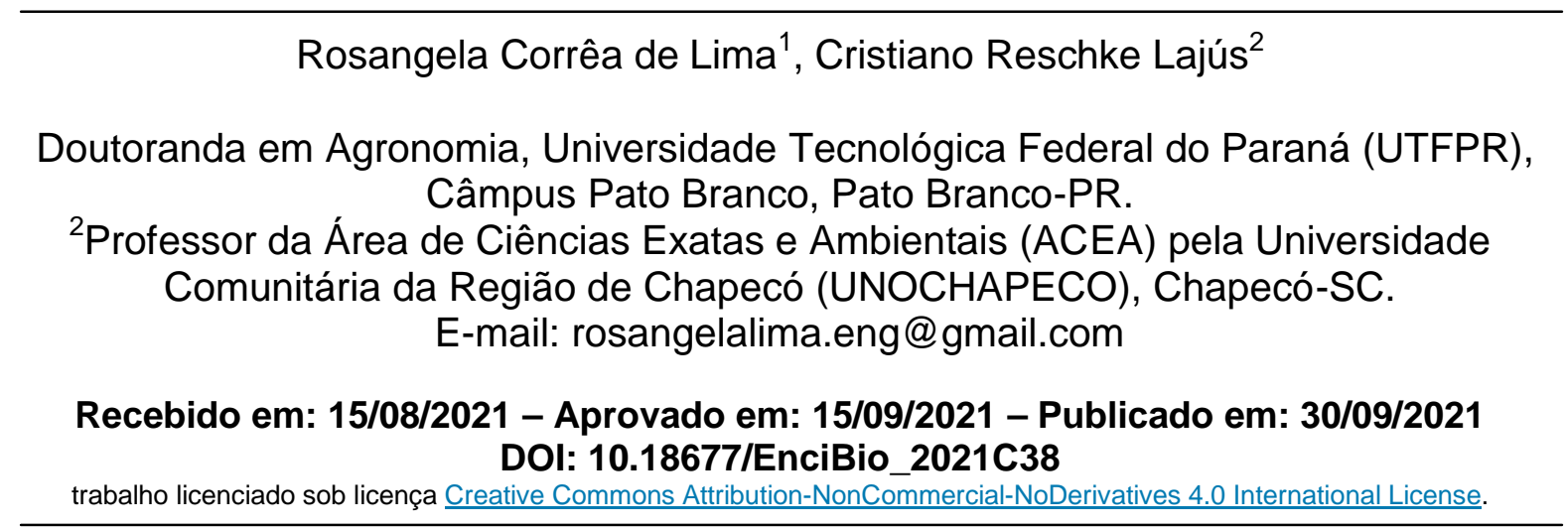

\section{RESUMO}

Algumas espécies utilizadas como adubos verdes, tem sido objeto de estudo, por apresentarem possíveis efeitos alelopáticos sobre a cultura de grãos sucessora. É o caso do nabo forrageiro que tem sido empregado na região Sul do Brasil como material para adubação verde de inverno e planta de cobertura, em sistemas de cultivo conservacionistas como a semeadura direta e o cultivo mínimo. O objetivo deste trabalho foi avaliar os extratos vegetais brutos da parte aérea do nabo forrageiro em relação ao seu efeito alelopático sobre o crescimento inicial do milho. Os tratamentos foram distribuídos em Delineamento Inteiramente Casualizado (DIC), consistindo de cinco concentrações do extrato foliar: $100 \%$ (extrato concentrado) e diluídos com água destilada nas concentrações de $75 \%$ (25\% de água destilada e $75 \%$ do extrato), $50 \%$ (50\% de água destilada e $50 \%$ do extrato), $25 \%$ (75\% de água destilada e $25 \%$ do extrato); e $0 \%$ (tratamento controle - água destilada). Cada tratamento teve quatro repetições, considerando as três plantas centrais como plantas úteis. Ao final do experimento (sete dias) foram avaliados: estatura de plântula; largura da folha; comprimento da folha; diâmetro do colmo; comprimento da maior raiz e massa seca total. Os dados foram submetidos à análise de variância e análise de regressão. Extrato obtido da parte aérea do Raphanus sativus L. contém potencial alelopático para o crescimento inicial da cultura do milho. A concentração de $25 \%$ de extrato de Raphanus sativus L. causou efeito inibitório em todas as variáveis analisadas, sendo que, quanto maior a concentração, maior foi à ação alelopática.

PALAVRA-CHAVE: Ontogenia. Rotação de culturas. Efeito inibitório. 


\title{
ALLELOPATHIC POTENTIAL OF EXTRACTS FROM THE AERIAL PART OF FORAGE TURNIP (Raphanus sativus L.) ON THE INITIAL GROWTH OF CORN (Zea mays L.) IN VEGETATION HOME
}

\begin{abstract}
Some of the species used as green manure have been studied for presenting possible allopathic effects on the next crop as is the case with forage turnips, which is used in the Southern Brazil as winter green manure and cover crop in conservation cropping systems such as no-till and minimum till. This work aims to evaluate crude vegetable extracts of forage turnips leaf in relation to its allelopathic effect on the initial growth of corn. Treatments were distributed in a Completely Randomized Design (CRD), consisting of five concentrations of leaf extract: $100 \%$ (concentrated extract) and diluted with distilled water in the concentrations of $75 \%$ (25\% distilled water and $75 \%$ extract), $50 \%$ (50\% distilled water and 50\% extract), 25\% (75\% diluted water and $25 \%$ extract) and $0 \%$ (control treatment - distilled water). Each treatment had four replications considering as useful the three central plants. By the end of experiment (seven days) plants were assessed for height, leaf width, leaf length, stem diameter, root length and total dry matter. Data were then assessed by analysis of variance and analysis of regression. Extract obtained from the aerial part of Raphanus sativus L. contains allelopathic potential for the initial growth of the corn crop. The $25 \%$ concentration of Raphanus sativus L. extract caused an inhibitory effect on all analyzed variables, and the higher the concentration, the greater the allelopathic action.
\end{abstract}

KEYWORDS: Ontogeny. Crop Rotation. Inhibitory Effect.

\section{INTRODUÇÃO}

As práticas conservacionistas têm ganhado cada vez mais espaço nos sistemas agrícolas do Brasil. Uma vez que a população mundial exige mudanças significativas nos sistemas produtivos, os quais torne-os mais sustentáveis, existe uma demanda crescente por produção de alimentos. Desta forma, deve-se pensar estratégias que visem tanto à produção de alimentos, garantindo a segurança alimentar, bem como, a sustentabilidade dos sistemas agrícolas a longo prazo e a conservação dos recursos naturais (EMBRAPA, 2018).

Dentre as práticas agrícolas que atendem essas premissas está o sistema plantio direto (SPD). Este por sua vez, usa como base a manutenção de palhada sobre o solo, semeadura direta, rotação de culturas e utilização de plantas de cobertura (DENARDIN et al., 2011). Neste sentido as plantas de cobertura desempenham papel fundamental no sucesso do SPD, estas promovem melhorias nos atributos físicos, químicos e biológicos do solo, benéficos através da ciclagem de nutrientes, proteção contra a erosão e incrementos importantes na matéria orgânica do solo (LAMAS, 2017). Por outro lado, as plantas de cobertura podem inibir a germinação de plantas daninhas, tanto pelo efeito físico da palhada, como pelo efeito alelopático. Assim como ocorre com as plantas daninhas, pode ocorre efeito inibitório na germinação também em plantas de interesse comercial, com a cultura do milho, soja, feijão entre outras.

A alelopátia é definida como um processo pelo qual os produtos do metabolismo secundário de um determinado vegetal são liberados, impedindo a germinação e o desenvolvimento de outras plantas relativamente próximas (SOARES; VIEIRA, 2000). Os efeitos alelopáticos são mediados por substâncias que pertencem a diferentes ENCICLOPÉDIA BIOSFERA, Centro Científico Conhecer - Jandaia-GO, v.18 n.37; p. 424 2021 
categorias de compostos secundários. Os recentes avanços na química de produtos naturais, por meio de métodos modernos de extração, isolamento, purificação e identificação, têm contribuído bastante para um maior conhecimento desses compostos secundários, os quais podem ser agrupados de diversas formas (FERREIRA; ÁQUILA, 2000).

A liberação desses compostos no agroecossistema pode ocorrer por: i) volatilização de substâncias provenientes de estado vegetativo; ii) lixiviação, através da chuva, de toxinas solúveis em água, da parte aérea ou de tecidos subterrâneos; iii) dos tecidos vegetais em decomposição e, iv) por exsudação do sistema radicular (MEDEIROS; LUCCHESI, 1993). Dessa maneira, busca-se compreender os efeitos que diferentes palhadas depositadas sobre o solo, proveniente da rotação de cultura e da semeadura direta, proporcionam a cultura subsequente. Esses efeitos podem ser positivos e negativos influenciando a germinação, crescimento inicial e consequentemente no rendimento da cultura.

Neste contexto, o nabo forrageiro (Raphanus sativus L.) apesar de apresentar vários benéficios aos sistemas produtivos e ser amplamente utilizado sobre cobertura de solo na região Sul do Brasil, apresenta características que podem inibir ou retardar a germinação de sementes da cultura sucessora, diminuindo a produtividade. Segundo estudos já realizados, a cultura do nabo forrageiro apresenta efeito alelopático sobre outras espécies vegetais. Estudo como o desenvolvido por Silva et al. (2014), constataram que extrato de Raphanus sativus interferiu negativamente na capacidade de germinação de Lactuca sativa, isso se deve, segundo os autores à quantidade de fenóis e flavonóides presentes no extrato de Raphanus sativus. Ainda, Nunes et al. (2014), trabalhando com Raphanus sativus verificaram efeito alelopático em plântulas de Lactuca sativa, pepino e soja. Ainda, extratos aquosos de plantas de nabo forrageiro e outras plantas de cobertura apresentaram efeito alelopático em plântulas de milho interferindo no crescimento de radícula, parte aérea e massa seca (TOKURA; NÓBREGA, 2005).

Dessa forma este trabalho teve como objetivo avaliar o efeito alelopático do extrato vegetal da parte aérea do nabo forrageiro sobre o crescimento inicial da cultura do milho.

\section{MATERIAL E MÉTODOS}

O experimento foi conduzido no viveiro florestal da Universidade Comunitária da Região de Chapecó (UNOCHAPECÓ), no mês de setembro de 2012. As amostras de nabo forrageiro (Raphanus sativus L.), foram coletadas no mês de agosto de 2012. A coleta foi realizada em propriedades rurais do município de Quilombo, no estado de Santa Catarina.

Os extratos da parte aérea do nabo forrageiro foram obtidos conforme a metodologia proposta por Corsato et al. (2010). As avaliações referentes a ecofisiologia foram realizadas em plantas de milho (Zea mays L.) provenientes da semeadura em bandejas de polietileno com $10 \mathrm{~cm}$ de largura por $6,5 \mathrm{~cm}$ de comprimento, $5 \mathrm{~cm}$ de altura, contendo areia esterilizada em estufa $105 \mathrm{C}^{\circ}$ por quatro horas. Para cada bandeja utilizou-se $2.700 \mathrm{~g}$ (dois quilos e setecentos gramas) de areia.

A semeadura do milho foi realizada manualmente, com uma densidade de 15 sementes por bandeja (três linhas / cinco sementes), distribuída em espaçamento igual entre sementes e com profundidade de $1,5 \mathrm{~cm}$ (um centímetro e meio). Os tratamentos ENCICLOPÉDIA BIOSFERA, Centro Científico Conhecer - Jandaia-GO, v.18 n.37; p. 425 
foram distribuídos em Delineamento Inteiramente Casualizado (DIC), consistindo de cinco concentrações do extrato foliar: 100\% (extrato concentrado) e diluídos com água destilada nas concentrações de $75 \%$ (25\% de água destilada e $75 \%$ do extrato), $50 \%$ (50\% de água destilada e 50\% do extrato), 25\% (75\% de água destilada e $25 \%$ do extrato); e $0 \%$ (tratamento controle - água destilada). Cada tratamento teve quatro repetições, considerando as três plantas centrais como plantas úteis.

Posteriormente, foram colocadas na sala de germinação por sete dias, à temperatura de $25^{\circ} \mathrm{C}$. Ao final do experimento foram avaliados: estatura de plântula; largura da folha; comprimento da folha; diâmetro do colmo; comprimento da maior raiz e massa seca total.

A determinação da estatura da plântula foi realizada com a utilização de uma régua graduada em milímetros, medindo a distância entre o colo e o ápice da plântula. O diâmetro do colmo foi medido cinco centímetros acima do colo da plântula. Para isso, utilizou-se paquímetro digital com a leitura das unidades em milímetros. Para a medição do comprimento de raiz, utilizou-se uma régua graduada em milímetros. Com a utilização de uma proveta foi determinado o volume do sistema radical, em que o volume foi avaliado pela diferença entre o volume da água antes de colocar as raízes na proveta e depois. Pela diferença foi avaliado o volume, onde cada $\mathrm{mL}$ correspondeu a $1 \mathrm{~cm}^{3}$. A massa seca total foi obtida após secagem em estufa de circulação forçada de ar a $65^{\circ} \mathrm{C}$, até atingirem peso constante, procedendo à pesagem em balança analítica eletrônica $(0,001 \mathrm{~g})$.

Os dados foram submetidos à análise de variância (ANOVA) e análise de regressão. Para a escolha dos modelos matemáticos foram considerados os resultados da análise de regressão, o coeficiente de determinação $\left(R^{2}\right)$ e criteriosa observação dos dados obtidos.

\section{RESULTADOS E DISCUSSÃO}

Todas as concentrações do extrato de nabo forrageiro proporcionaram efeitos inibitórios no crescimento inicial de plântulas de milho, ajustando-se ao modelo quadrático de regressão, para as variáveis, estatura de plântula, comprimento da maior raiz, comprimento e largura da folha e massa seca total e ao modelo cúbico de regressão as variáveis, diâmetro do colmo e volume de raiz.

Constatou-se que a testemunha obteve os melhores resultados em todas as variáveis analisadas (estatura de plântula, comprimento da maior raiz, volume de raiz, diâmetro do colmo, comprimento e largura da folha e massa seca total). As diferentes doses utilizadas de extratos de nabo forrageiro interferiram negativamente no crescimento inicial das plântulas de milho, influenciando em $99 \%$ para à variável estatura de planta (ET) e $94 \%$ para o comprimento da maior raiz (CMR), conforme mostra a Figura 1. Observou-se, portanto que as variáveis ET e CMR obtiveram um comportamento quadrático, ou seja, à medida que se aumentava a concentração do extrato de nabo forrageiro a influencia sobre o crescimento inicial foi maior, o que ocasionou um menor crescimento. 
FIGURA 1. Estatura de planta (ET) e Comprimento da maior raiz (CMR) de Zea mays L. sob diferentes doses de extrato alcoólico de Raphanus sativus $L$.

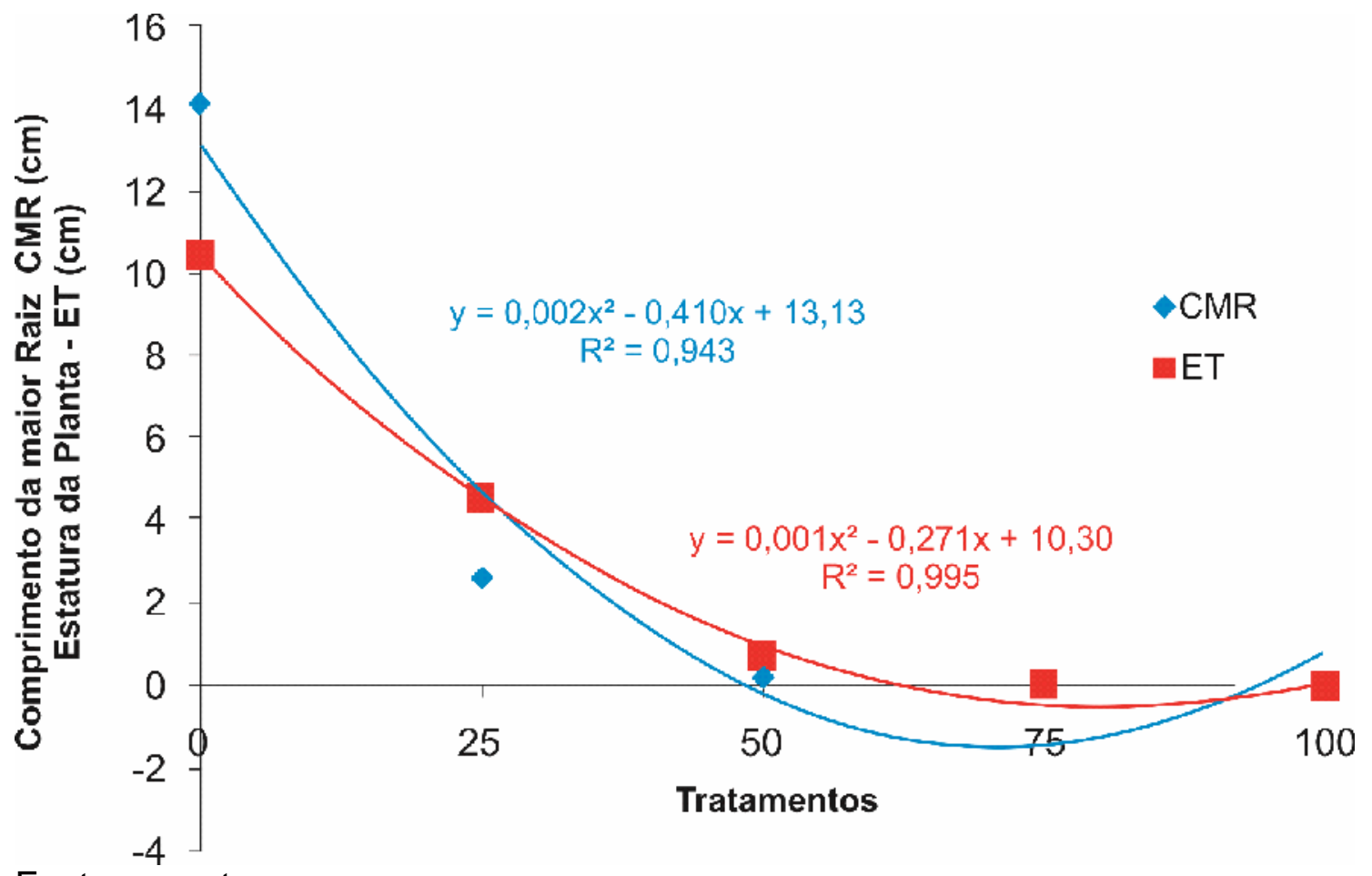

Fonte: os autores.

Esse efeito está relacionado com substâncias liberadas pela planta que podem afetar várias fases do desenvolvimento de algumas espécies que são sensíveis a estes compostos. Segundo Carvalho et al. (1993), ao longo dos anos tem se comprovado que as plantas produzem substâncias químicas com propriedades alelopáticas, que quando liberadas em quantidades suficientes, causam efeito alelopáticos que podem ser observados na germinação, no crescimento e no desenvolvimento de plantas. Para Ferreira e Áquila (2000), as alterações nos padrões de germinação devido à ação dos aleloquímicos refletem em alterações de rotas metabólicas, modificando processos importantes para o desenvolvimento do embrião, afetando a ontogênese.

Estes resultados estão de acordo com os encontrados por Almeida (1991), testando a influência dos extratos aquosos de nabo forrageiro e de colza sobre espécies silvestres. Este autor verificou que ambos reduziram os parâmetros analisados e em alguns casos anularam a germinação de algumas espécies. Esses dados corroboram também com os de Schneider e Cruz-Silva (2012), no qual o nabo forrageiro apresentou efeito alelopático sobre o desenvolvimento do milho, inibindo o comprimento da parte aérea e da raiz na concentração mais alta (30\%) quando preparado extratos na forma de lixiviação. De acordo com Nery et al. (2013), avaliando o efeito alelopático de plântulas de nabo forrageiro sobre a germinação de suas próprias sementes, constatou-se que a germinação não foi afetada, ao contrário do que ocorreu com as sementes de alface, em que o efeito inibitório causou anormalidades em $87 \%$ das plântulas de alface em concentrações de $10 \%$. 
Em relação às variáveis: comprimento da folha (CF) e largura da folha (LF) (Figura 2), a influencia pela utilização do extrato foi de 98 e $90 \%$ respectivamente. Verificou-se, portanto que a testemunha obteve os melhores resultados, quando comparado com os demais tratamentos que produziram efeito inibitório em todas as concentrações utilizadas e quanto maior a concentração maior foi este efeito. Neste sentido, muitos estudos têm demostrado que diferentes extratos apresentam significativos efeitos no desenvolvimento inicial, reduzindo a área foliar de espécies de plantas (JABRAN et al., 2015; ALGANDABY; EL-DARIER, 2018). Ainda, a intensidade da atividade inibitória de compostos aleloquímicos depende da dose, ou seja, quanto mais alta ou concentrada for a dose, maior o efeito sobre a variável analisada (ISLAM et al., 2018; ISLAM et al., 2019; ABD-ELGAWAD et al., 2020; MOUSAVI et al., 2021).

FIGURA 2. Comprimento da folha (CF) e Largura da folha (LF) de Zea mays L. sob diferentes doses de extrato alcoólico de Raphanus sativus $\mathrm{L}$.

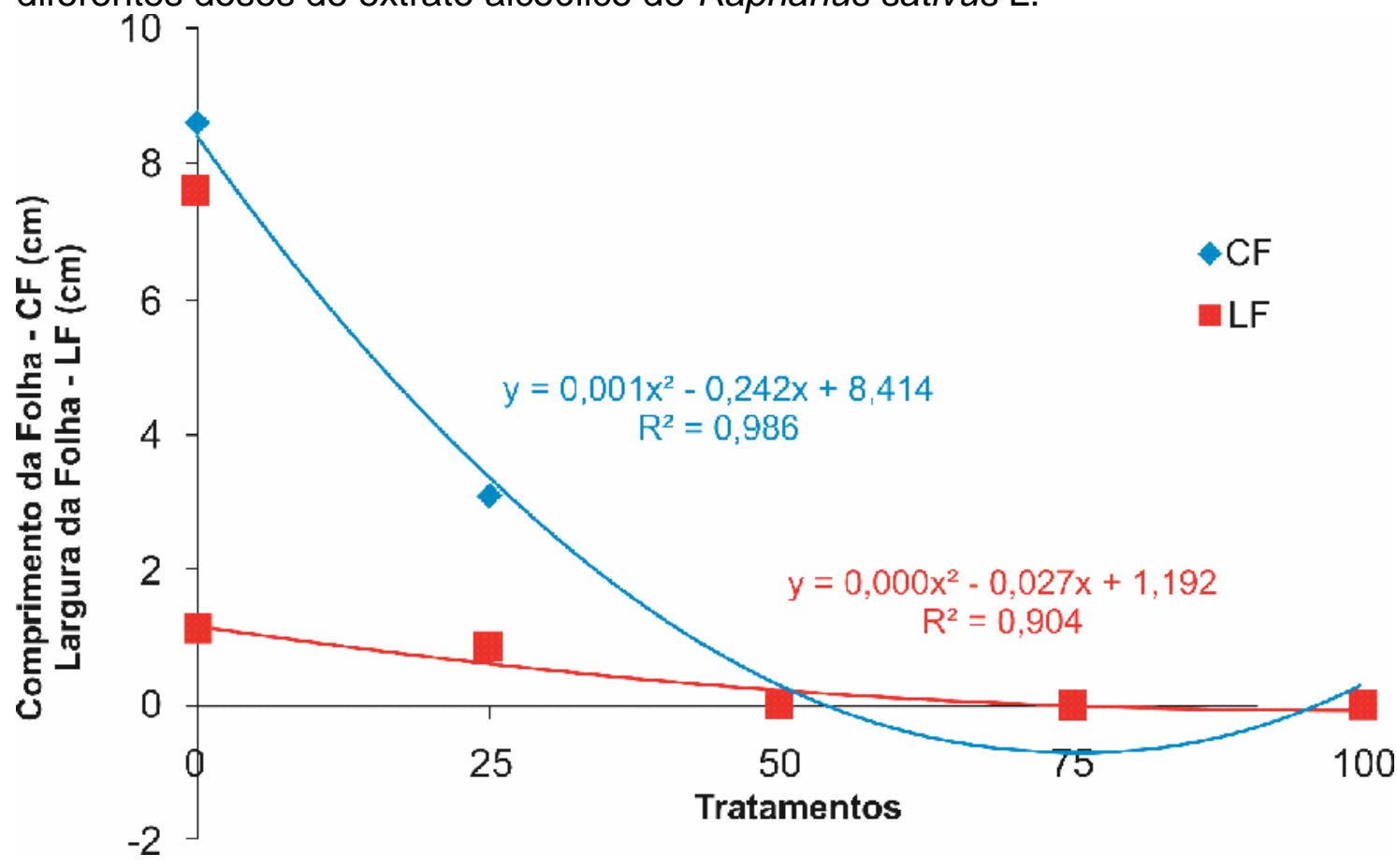

Fonte: os autores.

Constatou-se, portanto, que resultados obtidos neste trabalho assemelham-se aos encontrados por outros autores que também trabalharam com nabo forrageiro ou espécies da mesma família. Silva et al. (2011), verificaram que plantas de camelina, que pertencem a mesma família do nabo forrageiro, possui interferência alelopática sobre o desenvolvimento do picão-preto. Portanto, o efeito negativo proporcionado pela ação dos compostos químicos do nabo forrageiro no crescimento inicial das plantas é evidenciado, assim como na cultura no milho neste estudo.

Para as variáveis: volume de raiz (VR) e diâmetro do colmo (DC) (Figura 3) observou-se que o extrato de nabo forrageiro influenciou negativamente no crescimento das plântulas de milho em $99 \%$ e $97 \%$ respectivamente, adequando-se ao modelo 
cúbico de regressão. Este resultado pode ser reflexo do contato direto da raiz com os produtos fitoquímicos liberados pelos extratos, além de possuírem tecido mais permeável que outros órgãos, aumentando o efeito inibitório dos compostos químicos liberados do extrato (ISLAM et al., 2018; ISLAM et al., 2019). Ademais, o nabo forrageiro, é uma planta rica em compostos fenólicos (JAHANGIR et al., 2009), esses compostos modificam a permeabilidade das membranas celulares da raiz, diminuem o metabolismo energético e inibem a divisão celular e ramificação da raiz (MARCHIOSI et al., 2020), afetando diretamente o crescimento inicial.

FIGURA 3. Volume de raiz (VR) e Diâmetro do colmo (DC) de Zea mays L. sob diferentes doses de extrato alcoólico de Raphanus sativus $\mathrm{L}$.

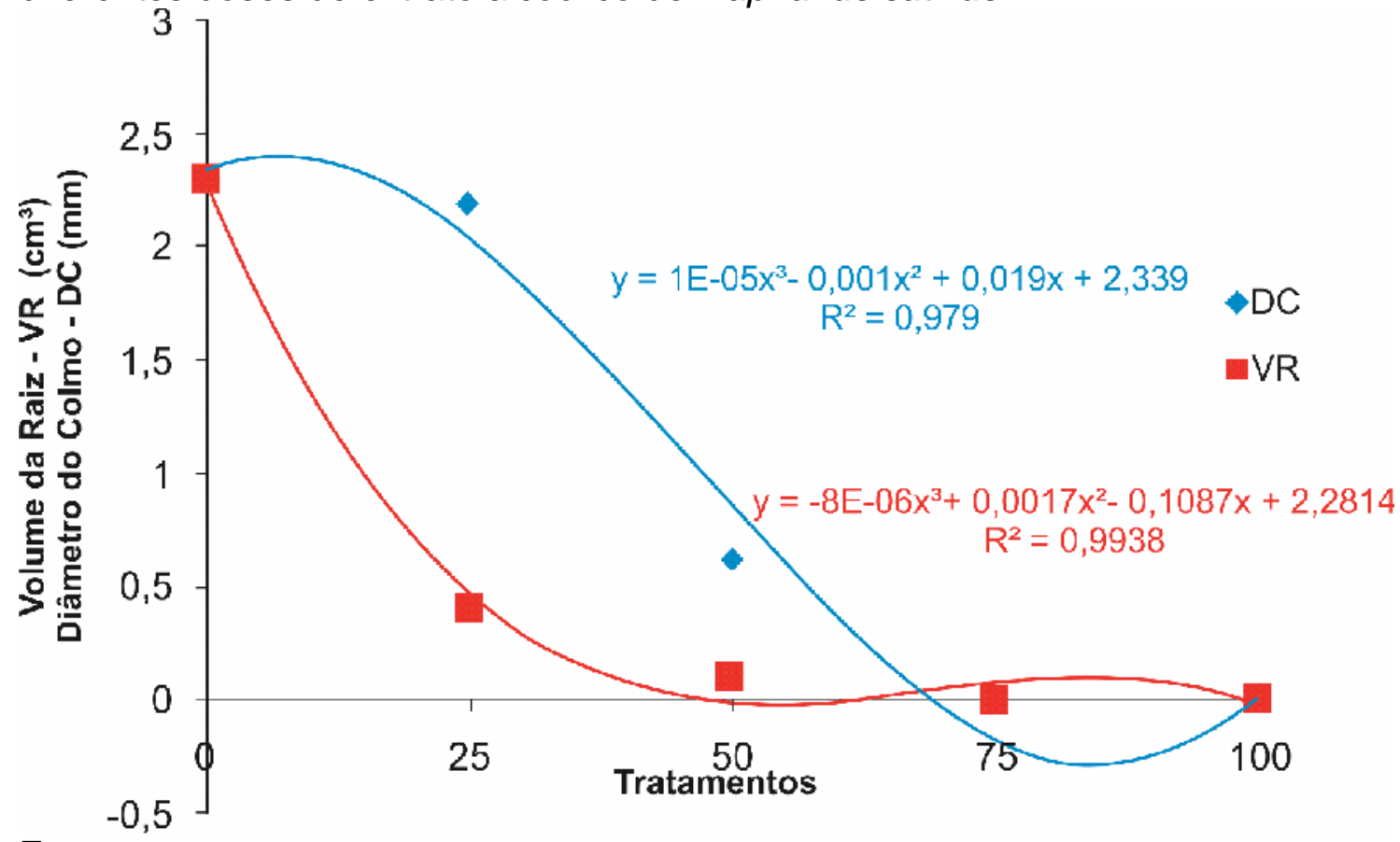

Fonte: os autores.

Outros estudos também verificaram efeito sobre o desenvolvimento das raízes de outras plantas. Segundo Morais et al. (2012) plantas inteiras de canola e da parte aérea de nabo forrageiro apresentaram redução no acúmulo de matéria seca da raiz (MSR) de picão preto.

Para a variável massa seca total (MST) a testemunha foi o que obteve o maior acúmulo de matéria seca com 0,1g (Figura 4). Para a dose $25 \%$ de extrato houve um acúmulo de $0,03 \mathrm{~g}$, sendo que não houve acúmulo de matéria seca para os demais tratamentos. 
FIGURA 4. Massa seca total (MST) de Zea mays L. sob diferentes doses de extrato alcoólico de Raphanus sativus L.

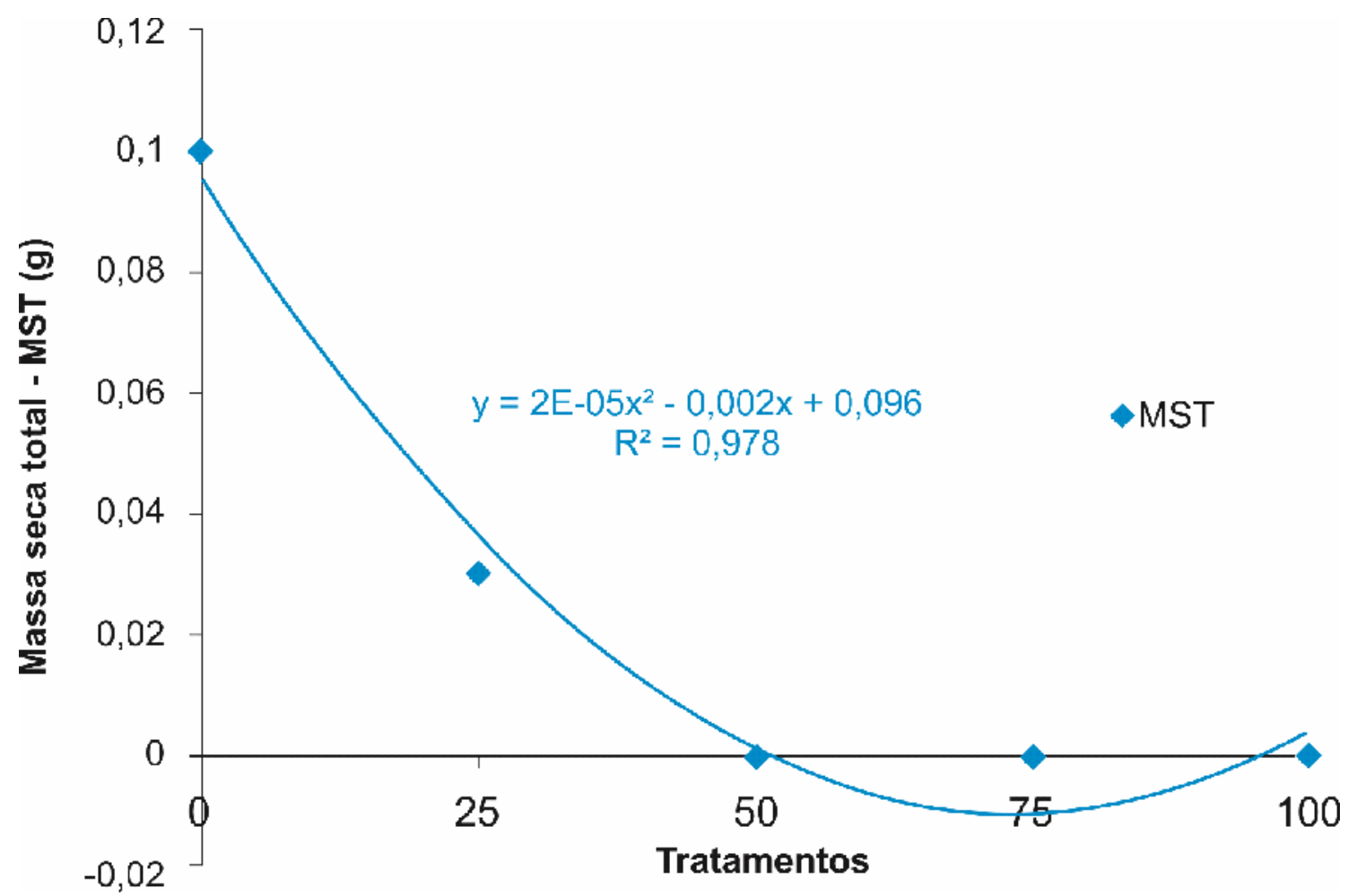

Fonte: os autores.

A parte aérea da cultura do milho é diretamente afetada pelo efeito das concentrações avaliadas neste estudo, refletindo em baixo acúmulo de MST. Uma vez que, a formação e desenvolvimento inicial das raízes seja afetado negativamente, é esperado que a parte aérea também tenha o mesmo efeito. Tokura e Nóbrega (2005), avaliando diferentes coberturas vegetais, inclusive o nabo forrageiro, constataram que quanto maior a concentração do extrato, maior foi o efeito sobre o crescimento da radícula, parte aérea e massa seca das plantas de milho.

Assim, como o nabo forrageiro possui efeito negativo sobre o crescimento inicial do milho, outras plantas de cobertura também tem sido objeto de estudo pelo seu efeito alelopático, tanto na cultura do milho como em outras culturas de interesse comercial. Em trabalho realizado por Araújo et al. (2011), constatou-se que a Crotalária juncea promoveu significativa ação alelopática sobre as sementes de milho e feijão. Ainda, Ribeiro et al. (2019), avaliando o efeito alelopático do girassol, verificaram que o girassol afetou negativamente a germinação e vigor das sementes de milho com extratos em concentrações acima de $25 \%$. De acordo com estudo realizado por Roncatto e Viecelli (2009), a cobertura do girassol possui efeito alelopático sobre o desenvolvimento do milho, sendo que a parte aérea é a mais sensível aos compostos aleloquímicos liberados pelo girassol. Ademais, avaliando a cultura da soja verificou-se que o peso seco da soja foi muito alterado pelo extrato aquoso da folha da mamona (SILVA et al., 2016). 
De forma geral, todas as plantas produzem compostos alelopáticos, porém, variam em quantidade e qualidade de espécie para espécie, e a tolerância ou resistência a esses compostos também pode ser específica, havendo espécies mais sensíveis que outras (FERREIRA; ÁQUILA, 2000), podendo ser esse o fator que explica os diferentes resultados observados em diferentes trabalhos.

\section{CONCLUSÃO}

Extrato obtido da parte aérea do Raphanus sativus L. contém potencial alelopático para o crescimento inicial da cultura do milho. A concentração de $25 \%$ de extrato de Raphanus sativus L. causou efeito inibitório em todas as variáveis analisadas, sendo que, quanto maior a concentração, maior foi à ação alelopática.

\section{REFERÊNCIAS}

ALMEIDA, F. S. Efeitos alelopáticos de resíduos vegetais. Pesquisa Agropecuária Brasileira, v. 26, n. 2, p. 221-236. 1991. Disponível em: <http://seer.sct.embrapa.br/index.php/pab/article/view/3333/666>.

ABD-ELGAWAD, A.M.; EL GENDY, A.E.-N.G.; ASSAEED, A.M.; AL-ROWAILY, S.L.; ALHARTHI, A.S. et al. Phytotoxic Effects of Plant Essential Oils: A Systematic Review and Structure-Activity Relationship Based on Chemometric Analyses. Plants, v. 10, n. 1, p. 36, 2020. Disponível em: <https://www.mdpi.com/2223-7747/10/1/36/htm>. doi: 10.3390/plants 10010036

ALGANDABY, M.M.; EL-DARIER, S.M. Management of the noxious weed; Medicago polymorpha L. via allelopathy of some medicinal plants from Taif region, Saudi Arabia. Saudi Journal of Biological Sciences, v. 25, n. 7, p. 1339-1347, 2018. Disponível em: <https://www.sciencedirect.com/science/article/pii/S1319562X16000607>. doi: 10.1016/j.sjbs.2016.02.013

ARAÚJO, E. D. O.; SANTANA, C. do N.; SANTO, C. L. do E. Potencial alelopático de extratos vegetais de Crotalaria juncea sobre a germinação de milho e feijão. Revista Brasileira de Agroecologia, v. 6, n.1, p. 108-116, 2011. Disponível em: <https://orgprints.org/id/eprint/23096/1/Ara\%C3\%BAjo_Potencial.pdf>.

CARVALHO, S.I.C.; NASCIMENTO JÚNIOR, D.; ALVARENGA, E. M.; REGAZZI, A. J. Caracterização dos efeitos alelopáticos de Brachiaria brizantha cv. Marandu no estabelecimento das plantas de Stylosanthes guianensis var. vulgaris cv. Bandeirante. Revista Sociedade Brasileira de Zootecnia, v. 22, n. 6, p. 930-937, 1993. Disponível em: <http://www.sbz.org.br/revista/artigos/623.pdf>.

CORSATO, J. M.; FORTES, A. M. T.; SANTORUM, M.; LESZCZYNSKI, R. Efeito alelopático do extrato aquoso de folhas de girassol sobre a germinação de soja e picãopreto. Semina: Ciências Agrárias, v. 31, n. 2, p. 353-360, 2010. Disponível em: <https://www.redalyc.org/pdf/4457/445744096008.pdf>. 
DENARDIN, J. E.; KOCHHANN, R. A.; SILVA JUNIOR, J. P. da; WIETHÖLTER, S.; FAGANELLO, A. et al. Sistema plantio direto: evolução e implementação. In: PIRES, J. L. F.; VARGAS, L.; CUNHA, G. R. da (Ed.). Trigo no Brasil: bases para produção competitiva e sustentável. Passo Fundo: Embrapa Trigo, 2011. cap.7, p. 185-215. Disponível em: <https://www.alice.cnptia.embrapa.br/handle/doc/932201>.

EMBRAPA. Empresa Brasileira de Pesquisa Agropecuária. Visão 2030: o futuro da agricultura brasileira. - Brasília, DF: Embrapa, 2018. 212 p. Disponível em: <https://www.embrapa.br/documents/10180/9543845/Vis\%C3\%A30+2030++0+futuro+d a+agricultura+brasileira/2a9a0f27-0ead-991a-8cbf-af8e89d62829?version=1.1>

FERREIRA, A.G.; ÁQUILA, M.E.A. Alelopatia: uma área emergente da ecofisiologia. Revista Brasileira de Fisiologia Vegetal, v. 12 (Edição especial), p. 175-204. 2000. Disponível em: <https://www.academia.edu/1368260/Alelopatia_uma_\%C3\%A1rea_emergente_da_eco fisiologia>.

ISLAM, A. K. M.M.; HASAN, M.; MUSHA, M.H.; UDDIN, K.; JURAIMI, A.S. et al. Exploring 55 tropicais medicinal plant species available in Bangladesh for their possible allelopathic potentiality. Annals of Agricultural Sciences, v. 63, n. 1, p. 99-107, 2018. Disponível em: <https://www.sciencedirect.com/science/article/pii/S0570178318300150>. https://doi.org/10.1016/j.aoas.2018.05.005

ISLAM, A.K.M.M.; HASAN, M.; YEASMIN, S.; ABEDIN, A.; KADER, A. et al. Bioassay screening of sawdust obtained from selected tropical tree species for allelopathic properties and their field performance against paddy weeds. Fundamental and Applied Agriculture, v. 4. n. 3, p. 906-915, 2019. Disponível em: https://www.ejmanager.com/mnstemps/112/112-1561571080.pdf?t=1627069801 >. doi: $10.5455 /$ faa. 54326

JABRAN, K.; MAHAJAN, G.; SARDANA, V.; CHAUHAN, B.S. Allelopathy for weed control in agricultural systems. Crop Protection, v. 72, p. 57-65, 2015. Disponível em:<https://edisciplinas.usp.br/pluginfile.php/4004102/mod_resource/content/3/alelopati a\%20Jabran\%202015.pdf>. doi:10.1016/j.cropro.2015.03.004

JAHANGIR M.; KIM, H. K.; CHOI, Y. H; VERPOORTE, R. HealthAffecting Compounds in Brassicaceae. Comprehensive Reviews in Food Science and Food Safety, v. 8, n. 2, p. 31-43, 2009. Disponível em: https://doi.org/10.1111/j.1541-4337.2008.00065.x

LAMAS, F. M. Plantas de cobertura: O que é isto? Embrapa: Empresa Brasileira de Pesquisa Agropecuária. Ministério da Agricultura, Pecuária e Abastecimento. 2017. Disponível em: <https://www.embrapa.br/busca-de-noticias/-/noticia/28512796/artigo--plantas-de-cobertura-o-que-e-isto>.

MARCHIOSI, R.; SANTOS, W.D. dos; CONSTANTIN, R.P.; LIMA, R.B. de; SOARES, A.R. et al. Biosynthesis and metabolic actions of simple phenolic acids in ENCICLOPÉDIA BIOSFERA, Centro Científico Conhecer - Jandaia-GO, v.18 n.37; p. 432 
plants. Phytochemistry Reviews, v. 19, p. 865-906, 2020. Disponível em: https://doi.org/10.1007/s11101-020-09689-2

MEDEIROS, A.R.M; LUCCHESI, A.A. Efeitos alelopáticos da ervilhaca (Vicia sativa L.) sobre a alface em testes de laboratório. Pesquisa Agropecuária Brasileira, v. 28, n. 1, $\quad$ p. $\quad 9-14.01993 . \quad$ Disponível <https://seer.sct.embrapa.br/index.php/pab/article/view/3855/1146>.

MORAIS, P.V.D.; AGOSTINELLO, D.; PANAZZO, L. E.; GALON, L.; OLIVEIRA, C. et al. Potencial alelopático de extratos aquosos de culturas de cobertura de solo na germinação e desenvolvimento inicial de Bidens pilosa. Ciências Agrárias, v. 33, n. 4, p. $1299-1314, \quad 2012.2$ Disponível em: < https://www.redalyc.org/articulo.oa?id=445744114031 > . doi: 10.5433/16790359.2012v33n4p1299

MOUSAVI, S.S.; KARAMI, A.; HAGHIGHI, T.M.; ALIZADEH, S.; MAGGI, F. Phytotoxic Potential and Phenolic Profile of Extracts from Scrophularia striata. Plants, v. 10, n.1, p. 135, 2021. Disponível em: <https://www.mdpi.com/2223-7747/10/1/135/htm>. doi: https://doi.org/10.3390/plants10010135

NERY, M.C.; CARVALHO, M.L.M.; NERY, F.C.; PIRES, R.M.O. Potencial alelopático de Raphanus sativus L. var. oleiferus. Informativo ABRATES, v. 23, n. 1, p. 15-20, 2013. Disponível em: <https://www.abrates.org.br/img/informations/950ff7fa-c03a-4960-a520f6cb0870babe_IA\%20vol.23\%20n.1.pdf>.

NUNES, J. V. D.; MELO, D. M.; NÓBREGA, L. H. P.; LOURES, N. T. P.; SOSA, D. E. F. Atividade alelopática de extratos de plantas de cobertura sobre soja, pepino e alface. Revista Caatinga, v. 27, n. 1, p. 122-130, 2014. Disponível em: < https://periodicos.ufersa.edu.br/index.php/caatinga/article/view/2990/pdf_94>.

RIBEIRO, J. P. O.; VASCONCELOS, G. M. P. de V. e; PARRELLA, N. N. L. D.; SILVA, A. F. da. Efeito alelopático do extrato aquoso de folhas e caule de girassol sobre a germinação de milho e sorgo. Revista Fitos, v. 13, n. 3, p. 192-199, 2019. Disponível em: <https://revistafitos.far.fiocruz.br/index.php/revistafitos/article/view/827/612> doi: 10.32712/2446-4775.2019.827

RONCATTO, F.; VIECELLI, C.A. Adubação verde de girassol sobre o desenvolvimento do milho. Cultivando o Saber, v. 2, n. 3, p. 1-6, 2009. Disponível em: <https://www.fag.edu.br/upload/revista/cultivando_o_saber/592726b9ca133.pdf>.

SCHNEIDER, C.T.; CRUZ-SILVA, C.T.A. Potencial alelopático do nabo forrageiro (Raphanus sativus L.) sobre o desenvolvimento do milho (Zea mays L.) e a aveia preta (Avena strigosa Schreb.). Revista Thêma et Scientia, v. 2, n. 1, p. 151-156, 2012. Disponível em: <https://www.fag.edu.br/upload/arquivo/1362061306.pdf>.

SILVA, J.; FORTES, A.M.T.; GOMES, F.M.; PINTO, T.T.; BONAMIGO, T. et al. Alelopatia de Camelina Sativa Boiss. (Brassicaceae) sobre a germinação e ENCICLOPÉDIA BIOSFERA, Centro Científico Conhecer - Jandaia-GO, v.18 n.37; p. 433 2021 
desenvolvimento inicial de Bidens pilosa (L.) e Glycine max (L.) Merr. Biotemas, v. 24, n. 4, p. 17-24, 2011. Disponível em: <http://dx.doi.org/10.5007/21757925.2011v24n4p17>. doi: 10.5007 / 2175-7925.2011v24n4p17

SILVA, R.F. da; BRESSAN, R.T.; ZILLI, B.M.; PILATTI, M.A.; SOUZA, S.N.M. de. et al. Allelopathic effect of aqueous extract of fresh leaf castor beans (Ricinus communis L.) applied to the beginning stage of soy (Glycine max L.) and safflower (Carthamus tinctorius L.). African Journal of Biotechnology, v. 15, n. 49, p. 2787-2793, 2016. Disponivel em: <https://www.ajol.info/index.php/ajb/article/view/149599>. doi: 10.5897 / AJB2016.15707

SILVA, R.M.G.; BRANTE, R.T.; SANTOS, V.H.M.; MECINA, G.F.; SILVA, L.P. Phytotoxicity of ethanolic extract of turnip leaves (Raphanus sativus L.). Bioscience Journal, v. 30, n. 3, p. 891-902, 2014. Disponível em: <http://www.seer.ufu.br/index.php/biosciencejournal/article/view/19530/14290>.

SOARES, G.L.G.; VIEIRA, T. R. Inibição da germinação e do crescimento radicular de alface (cv. Grand Rapids) por extratos aquosos de cinco espécies de Gleicheniaceae. Floresta e Ambiente, v. 7, n. 1, p. 180-197, 2000. Disponível em: < https://www.floram.org/article/588e21f2e710ab87018b45ac/pdf/floram-7-\%C3\%BAnico190.pdf>.

TOKURA, L. K.; NÓBREGA, L. H. P. Potencial alelopático de cultivos de cobertura vegetal no desenvolvimento de plântulas de milho. Acta Scientiarum Agronomy, v. 27, n. 2, $\quad$ p. 287-292, $2005 . \quad$ Disponível em: <https://periodicos.uem.br/ojs/index.php/ActaSciAgron/article/view/1847/1141>. 